\title{
A Review on Development and Operational Strategy of Fault Current Limiters
}

\author{
S.P. Janani Priyadharshna, T. Venkatesan \\ Department of Electrical and Electronics Engineering, K.S. Rangasamy College of Technology, \\ Tiruchengode, Tamil Nadu, India
}

\begin{abstract}
Distributed Generation (DG) plays a major role in existing power system. When such distributed generation system is interconnected with micro-grid improves voltage profile, power quality but at the same time results in fault conditions. Among various faults occurring in the power system, short circuit faults are the most predominant case. This results in the increase in flow of the fault current in the line. Also the equipments installed in such a line get damaged internally due to flow of excess fault current. Therefore in order to improve the transient conditions and limit the fault current to a manageable level, a device called Fault Current Limiters (FCLs) are being used in recent trend. This paper reviews about various fault current limiters, their development, characteristics and operating performance in the system. It gives a detailed knowledge about various operations performed by fault current limiters that is compared with other conventional techniques.
\end{abstract}

Keywords: distributed generation, short circuit fault, transient condition, fault current limiters

Copyright $\odot 2015$ Institute of Advanced Engineering and Science. All rights reserved.

\section{Introduction}

Electrical energy is the most essential form of energy in this existing world. Correspondingly, there is an increase in power consumption in the modern power system. As a result, there is an increase in power demand. Therefore, the sources of generation of electricity are being increasingly utilized in recent years. These sources of generation include both conventional and non-conventional energy resources. Solar energy, wind generators, tidal power, geothermal sources etc all forms the most prominent sources of electricity than conventional resources. Hence, Distributed Generation (DG) resources as mentioned earlier certainly play the most significant role in the generation of electrical power. When such distributed generation sources are interconnected to a distributed system results in the advancement of micro-grid [1]-[2]. A micro-grid, which forms a portion of the power system, normally a distributed system consists of one or more distributed generation units that are independent of the utility grid.

Integration of Distributed Generation with micro-grid improves the voltage profile, power quality and supports the load conditions. Consequently, their results in generation of fault currents which causes the overall system upset. Penetration of DG [3] into the system is proportional to the amount of fault current produced. Distributed generation integrated with micro-grid, though being eminent in recent years, this raises a series of challenges, the most dominant being the serious issue of transient conditions and consequently protection of the system is required [4].

Fault current forms the most existing transient condition in the system. Such fault current damages the equipments connected in the line to a certain extent. Transient conditions being very severe in micro-grid requires various protection techniques in the existing power system such as adaptive protection scheme, voltage based techniques, differential protection, distance protection, over-current protection and use of external devices [5]. In view of external devices, both conventional and recent devices are available. Air core reactors, fuses and circuit breakers form the conventional devices whereas Fault Current Limiters (FCLs) forms the most recent device for protection system. But in the case of conventional devices there exists many drawbacks as they are very prone to fault conditions. Hence this paper aims to bring the concepts of various external devices implemented in real time system for providing protection to a certain extent 


\section{Conventional Methods for Fault Current Protection Scheme}

The most commonly existing conventional devices for protection as explained earlier includes air core reactor, fuses and circuit breakers. These devices have been accepted worldwide which provides protection to a greater extent. Air core reactor [6] is used especially for current limiting means for decades. Though air core reactors are used extensively, the inductances required for further protection operation causes the size of reactor to increase proportionally. This forms one of the major drawbacks in such reactors. Consequently, this result in high voltage drops and ultimately requires cooling. The amount of current reduction depends upon the type of reactors used. Fuses are also most commonly and commercially used device. Fuses are more prone and sensitive to fault conditions where the flow of excessive current leads to the breakdown of the entire device. Hence such occurrence of breakdown leads to the replacement of fuses which forms the tedious task and time consuming. Circuit Breakers also perform the similar operation as mentioned above. But in this case CB allows the first cycle of peak current to flow through and starts its operation for the next cycle whereby the efficiency in limiting the fault current is not up to the level.

Therefore, in order to overcome all such drawbacks research has been going on in a particular device to be technically and economically suitable for protection. Such a device is called Fault Current Limiters (FCLs) which is defined literally to limit the fault current. This device forms a better solution for improving the transient conditions formed by the fault current and also enhances the system stability.

\section{Fault Current Limiters (FCLs)}

Fault current limiters are devices which limits the fault current to a lower manageable level. During normal operation, this limiter has very low impedance and during fault conditions, these limiters posses high impedance [7]. Fault current limiters can be placed in major three positions in the power grid (i.e) in the generation side which forms the main position (A), bus tie position (B) and feeder position (C) in Figure 1.

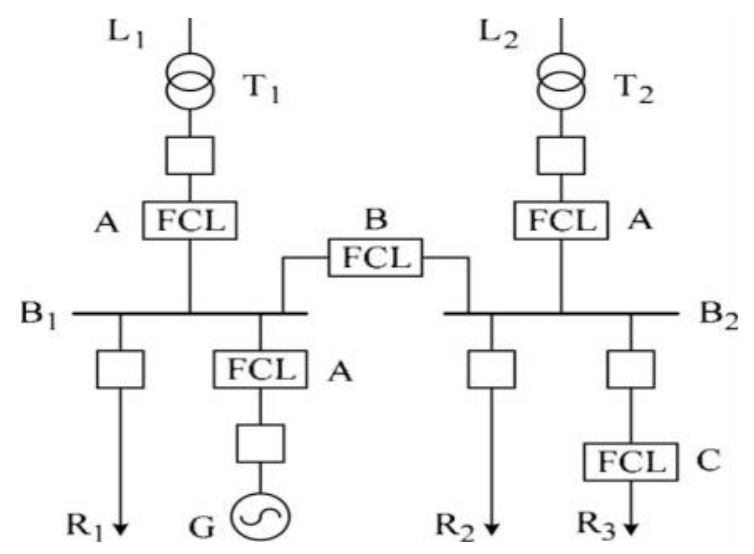

Figure 1. Positions of FCL in power grid

FCL placed in position $A$ helps to reduce fault current and at the same time causes voltage dips to be less severe. FCL in bus tie position B helps to maintain the voltage level on other unfaulted buses. FCL in feeder position C provides protection to overstressed equipment produced due to faulty conditions.

\section{Types of Fault Current Limiters (FCLs)}

There are different types of fault current limiters for protection purpose in the existing power system. They are

1. Pyrotechnic fault current limiter or Is- limiter 
2. Superconducting Fault Current Limiter (SFCL)

3. Solid State Fault Current Limiter (SSFCL)

4. Electromagnetic Dynamic Fault Current Limiter (EDFCL)

5. Hybrid Fault Current Limiter

Of which air core reactor and Is-limiter forms the most conventional means of protection that has been accepted world-wide. Superconducting Fault Current Limiter and Electromagnetic Dynamic Fault Current Limiter also have been designed and tested in the entire power system and analysis of such limiters along with their status of protection has been presented. Solid State Fault Current Limiter and Hybrid Fault Current Limiter form the next stage of limiters which are currently in research and development phase.

\subsection{Pyrotechnic Fault Current Limiter or Is- Limiter}

The Is-limiter which is the most conventional method of protection is the world's largest switching device with extremely short operating time. The function of Is-limiter is to first detect the fault current and limit the short circuit current during the first current rise itself and hence maximum short circuit current can never be reached. Is-limiter consists of measuring and tripping devices where the current flowing through this limiter is monitored by these devices. During the very first rise in the fault current, this device decides the necessity of tripping this Islimiter. Therefore, for such action to be performed, the instantaneous current and the rate of rise of current at the Is-limiter is being constantly measured and evaluated.

The function of Is-limiter can be well depicted through a single line diagram (Figure 2) where a short circuit downstream is obtained from an outgoing feeder breaker. Assuming a short circuit current of 31.5kA flows to the fault location through each transformer, therefore resulting in a total short circuit current of 63kA. The current through the Is-limiter during such an event is given as $i_{2}$.In such situation Is-limiter responds very rapidly, so that there is no contribution to the total peak short circuit current $\left(\mathrm{i}_{1}+\mathrm{i}_{2}\right)[8]$.

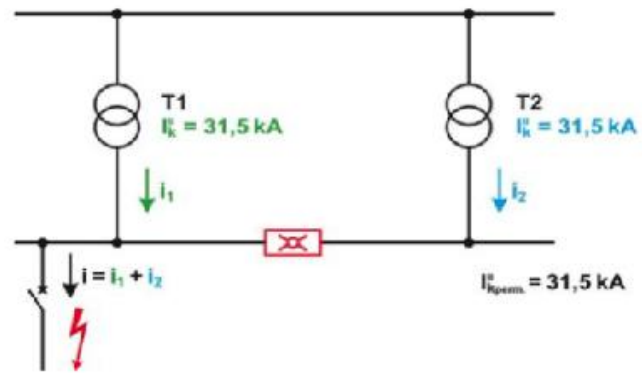

Figure 2. Single line diagram

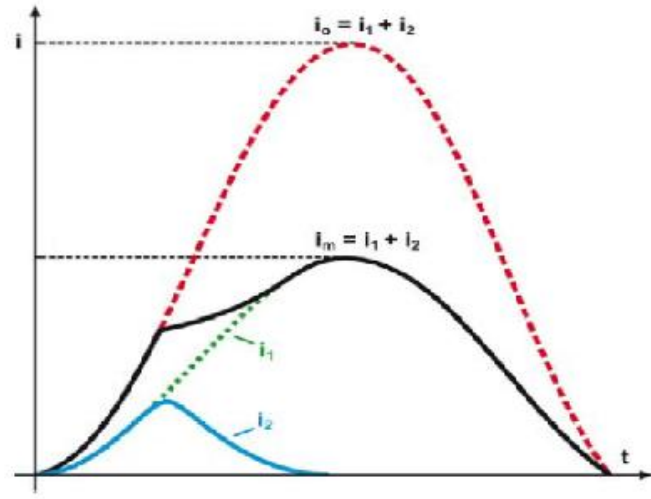

$\mathrm{i}_{0}=$ Total current without Is-limiter $\mathrm{i}_{\mathrm{m}}=$ Total current with Is-limiter

$\mathrm{i}=$ Short circuit current at fault location

Figure 3. Current limiting by Is-Limiter

Is-limiter (Figure 3 ) has been proven for its reliability and functions in thousands of installation since 1960 and accepted worldwide. Therefore few characteristics of Is-limiters are is that they reduce the substation cost, solves all sorts of short circuit problems in new substations and substation extensions, and provides optimum solution for interconnection of switchboards and substations [9].

\subsection{Superconducting Fault Current Limiter (SFCL)}

Superconducting fault current limiters form one of the most novel techniques for protection in accordance with limiters. K.Okaniwa et al., [10] proposed a superconducting fault current limiter which was developed and tested in the year of 1991. Initially 400V-100A class 
fault current limiter was developed which is wound with $\mathrm{AC}$ superconducting wire using $\mathrm{NbTi}$ filaments. Generally during normal state, the trigger coil is in superconducting state and under faulty conditions, as fault current exceeds the critical current the coil transits to normal state, as Figure 4.

High temperature superconducting FCL is the most existing SFCL in existing power system. Seungje Lee et al., [11] proposed the stability analysis of power system when SFCL is installed which forms the next stage after development process. Parameters were modeled in $440 \mathrm{~V}$ class prototype SFCL and the transient performance was solved by numerical methods. In this case, the problem of synchronization is solved by maintaining synchronism in both three phase fault and single phase line to ground fault.

Generally there exists two types of superconducting Fault current Limiters (SFCL).

1. Resistive type SFCL

2. Inductive type SFCL: a) shielded iron core type SFCL, and b) saturated iron core type SFCL

S. Nemdili et al., proposed the modeling of resistive type SFCL using Graphic User Interface (GUI) of MATLAB. Therefore, high temperature superconductors are used which includes electric field - current density (E-J) characteristics. Finally, it has been shown that this type of SFCL reduces 5.422 times the fault current according to the analysis [12]. In recent trend, resistive superconducting fault current limiter is dominant in $R \& D$ stage due its potential to be small and decrease in price of $2 \mathrm{G}$ coated conductors. YBCO (Yttrium- Barium- CopperOxide) coated conductors, Magnesium Diboride (MgB2) are some of the most commonly used conductors in this type [13]-[14].

Arsalan Hekmati proposed an inductive shield type SFCL which forms the most promising type of limiters. Here tunable shield type SFCL has been designed consisting of the second copper winding as a control winding that is being connected to an ac voltage source through a series resistance as depicted in the Figure 5. Two operating conditions such as normal operating condition and fault conditions are performed using this type of SFCL [15].

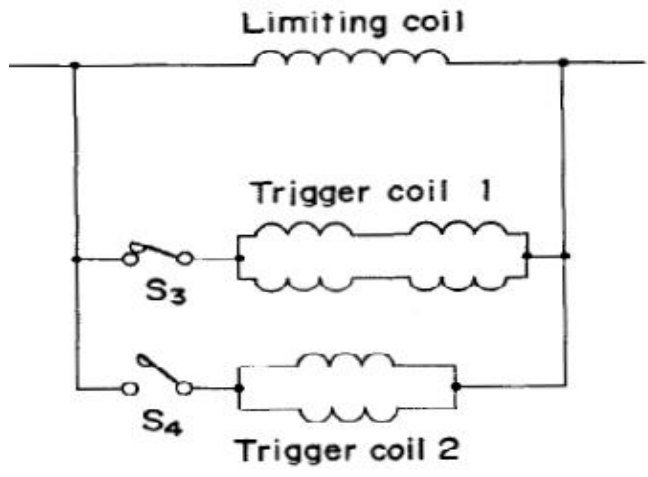

Figure 4. Circuit diagram for 400V-100A class limiter

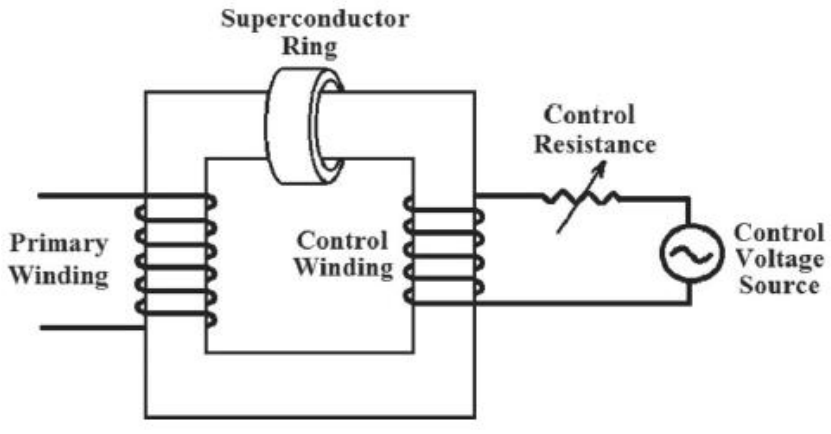

Figure 5. Tunable shield type-SFCL

Xiaoye Niu et al., proposed the structure and performance characteristics of Saturated Iron-core Superconducting Fault Current Limiter (SISFCL) as Figure 6 in which case there is no possibility of quenching in superconducting wires during the process of fault current limiting. The additional advantage is its fast recovery and immediate reaction under fault conditions. This limiter operates in such a way that under normal condition, the superconducting coil is provided with dc excitation in order to saturate the iron-cores and the ac windings are provided with low impedance. Under short circuit conditions, the dc source is cut off and both the iron-cores comes to a desaturated state and the ac windings are provided with high impedance to limit the short circuit currents [16]. 


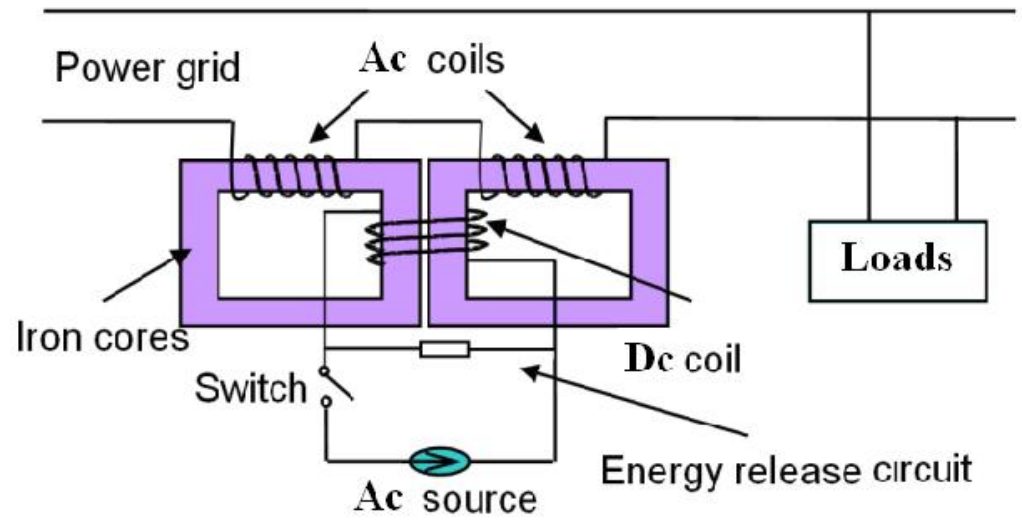

Figure 6. Schematic Diagram of Single-phase SISFCL.

\subsection{Solid state Fault Current Limiter (SSFCL)}

Solid State Fault Current Limiter (SSFCL) is proposed here consisting of power semiconductor devices consisting of desirable features such as high blocking voltage, low onstage voltage, low conduction loss and thermal management. Power semiconductor devices such as the GTO, IGBT, SCR, and IGCT are the most promising devices used in SSFCL. Generally SSFCL consists of thyristor controlled reactor and series capacitor where the former reduces the short circuit current and the latter increases the transmitted power. M. M. R. Ahmed et al., proposed the harmonic analysis of solid state fault current limiter which was the initial analysis performed in this limiter. Since solid state fault current limiters consist of power semiconductor devices, there occurs repetitive switching which leads to generation of harmonics and hence harmonic analysis is performed [17]. Solid state fault current limiters can be classified into three types as series switch type, bridge type and resonant type.

Teymoor Ghanbari et al., proposed high-performance bridge-type fault current limiter (BFCL) which is based on switched transformer-type DC reactor. This limiter operates when the load current exceeds the threshold value where the secondary side of the transformer is being opened by insulated gate bipolar transistor [18]. Ebrahim Farjah et al., proposed the development of a resonant type solid-state fault current limiter, as Figure 7.

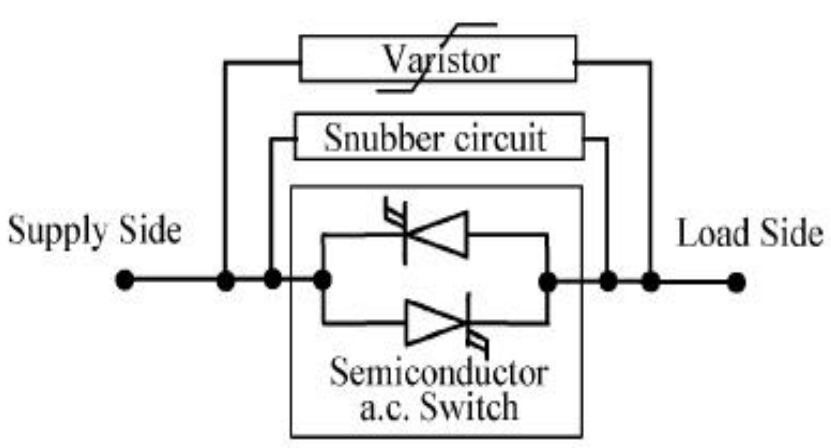

Figure 7. Construction of solid-state fault current limiter

This consists of both series and parallel resonant circuits that are being tuned to supply frequency. Under normal condition, very low impedance is provided through series resonant circuit and under fault conditions, SSFCL provides high impedance by parallel resonant circuit [19]-[20]. Ji-Seong Kang et al., proposed a new type of solid state fault current limiter where Magnetic Turn-Off (MTO) principle is used consisting of transformer cores and windings. MTO FCL forms the most practical technique to be implemented where it does not require any 
superconducting materials or additional complex cooling systems [21]. Transformer based solid state fault current limiter is proposed in [22]. Such limiter reduces the switching overvoltage. They also improve the power quality and simple in structure which relatively reduces its cost. The advantage of the proposed limiter is its lowest switching over voltages and power loss compared with other SSFCL.

As compared to the limiters described above, SSFCL forms the vital device in research and development (R\&D). Research is being on the power semiconductor device that is to be used in fault current limiter that limits both transient and sub transient currents in the first cycle.

\subsection{Electromagnetic Dynamic Fault Current Limiter (EDFCL)}

Emad S. Ibrahim proposed an electromagnetic circuit that consists of an iron-core and armature with an adjustable air gap. The characteristic of this limiter is that it automatically and instantaneously adjusts its own impedance which depends upon the magnitude of fault current. This limiter is referred to as "dynamic" as the impedance varies with current. In real time, the developed EMFCL can be applied in series with a transformer in order to limit the fault contribution from the source. In comparison with other fault current limiters, this device provides 3 functions of detection, commutation and limitation.

According to Figure 8 under normal conditions, the armature creates an air gap therefore resulting in low impedance due to external forces. Under fault conditions, the magnetic force of the flux exceeds the external force, therefore causes the armature to move and close the air-gap [23].

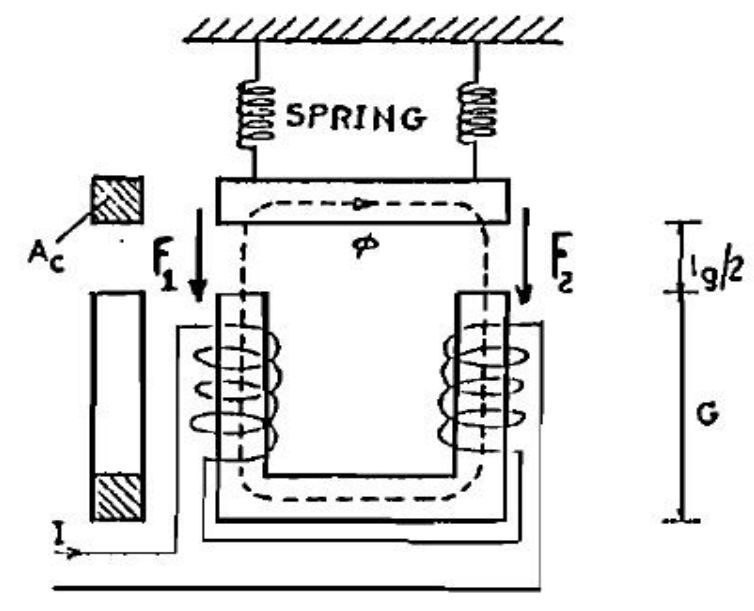

Figure 8. Electromagnetic Fault Current Limiter

Prafulla Rajabhau Deo et al., proposed a dynamic fault current limiter that has incremental impedance which is due to incremental permeability in the electromagnetic device [24].The main feature of dynamic fault current limiter is that it limits both first peak current and rms value of short circuit current. The operating criteria of this limiter is that it operates under ambient temperature of -22 to $55 \mathrm{deg} \mathrm{C}$ where superconductors requires $-320 \mathrm{~F}$ as cryogenic temperatures which implies that EDFCL being superior to SFCL.

\subsection{Hybrid Fault Current Limiters}

Hybrid fault current limiters were developed in the year of 2000 which combines superconducting fault current limiters and solid state fault current limiters. This hybrid type consists of superconductors that are used as a delayed reacting resistive limiting element which is done in parallel with the fast acting load switch [25]. In this case, superconductors carry the fault current only under switching and therefore the total loss of the system is comparatively less than other conventional SFCL. Therefore, cooling of such superconductors is essential which is provided by gaseous nitrogen that is feasible and flexible in operation. Power semiconductor

TELKOMNIKA Vol. 16, No. 1, October 2015: $145-153$ 
devices such as integrated gate commutated thyristors (IGCT) with superconducting fault current limiters is proposed as a hybrid device in [26]-[27]. The reliability of fast switch is being enhanced by this hybrid device where fast switch utilizes vacuum interrupter in order to open and close the primary power line. In this case, IGCT operates to remove the remanent current from vacuum interrupter thereby enhances the reliability.

Majid Ebrahimpour et al., proposed a fault current controller in addition to fault current limiters as depicted in Figure 9 when the penetration level of DG increases in the micro-grid. Fault current limiters limit the fault current but at the same time it must be controlled and maintained in a specified range.

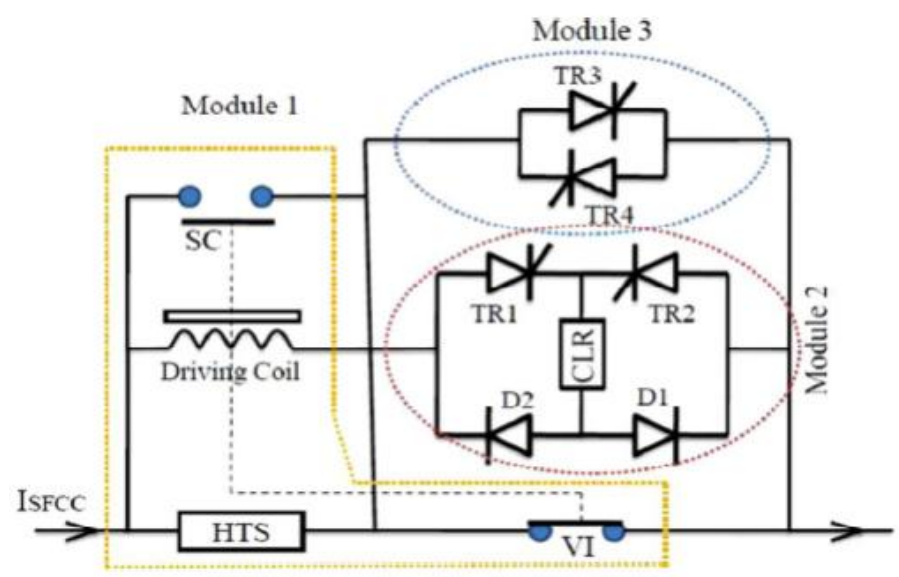

Figure 9: Hybrid Superconducting Fault Current Controller

From the above figure, module 1 consists of high temperature superconducting (HTS) element and fast switch where HTS element is used for fault sensing and current commutation. The current limiting reactor is introduced in module 2 comprising of solid state switches in order to limit the fault current. Module 3 is utilized to bypass the fault current during islanding mode of micro-grid [28]. In order to limit the transient fault current and shorten the acting time to limit the steady state fault current, hybrid bridge type SFCL is proposed in [29] using power electronics devices such as MOSFET,IGBT etc. The major advantage of the proposed device is its fast response that suits both fault occurrence and power system recovery and at the same time has the ability to limit both transient and steady state fault currents.

M. Firouzi et al., proposed a bridge-type SFCL that limits fault current without any delay and therefore smooth the surge current waveform. Fault conditions that are being considered here are phase-to- ground and phase-to-phase faults where the impact of the proposed device is shown by the performance of the distance relay [30].

\section{Conclusion}

As it has been very clearly seen that increase in penetration level of distributed generation units into micro-grid results in the occurrence of short circuit conditions and consequently the flow of the fault current takes place. In order to improve such transient conditions, fault current limiters were proposed which forms the most recent device used for protection. Research is being still going on fault current limiter device which overcomes the drawbacks faced by conventional protective devices. Therefore, in this paper survey has been made on the development and operational strategy of fault current limiters of those that is been already existing and those in R\&D stage. Lots of research work has to be carried out on solid state fault current limiters and hybrid fault current limiters which furthermore enhances the transient conditions in micro-grid. 


\section{References}

[1] Cameron W. Potter, Allison Archambault, Kenneth Westrick, Building a Smarter Smart Grid Through Better Renewable Energy Information, IEEE 2009

[2] Chandan Chakraborty, Herbert Ho-Chiang lu,, Dylan Dah-Chuan Lu, Power Converters, Control, And Energy Management For Distributed Generation, IEEE Transactions On Industrial Electronics, Vol. 62, No. 7, July 2015

[3] Qiang Fu, AdeINasiri,Vijay Bhavaraju, Ashish Solanki,Tarek Abdallah, Transition Management Of Microgrids With High Penetration Of Renewable Energy, IEEE Transactions On Smart Grid, Vol. 5, No. 2, March 2014

[4] N. Phuangpornpitaka, S. Tia, Opportunities and Challenges of Integrating Renewable Energy in Smart Grid System, Energy Procedia 34 ( 2013 ) 282 - 290

[5] G. Buigues, A. Dyśko, V. Valverde, I. Zamora and E. Fernández, Microgrid Protection: Technical challenges and existing techniques, International Conference on Renewable Energies and Power Quality (ICREPQ'13)

[6] John D. Leitch, Air-Core Reactors as Fault Limiting Means on High Interrupting Capacity Controllers, AIEE Transactions, volume 68, 1949.

[7] Office of Electricity Delivery and Energy Reliability, OE-1U.S. Department of Energy

[8] A. Brandt1, K.-H. Hartung1, R. Bockholt2 and V. Schmidt, Is-limiter: Limitation of short-circuit currents for maximum economic benefits

[9] ABB AG Calor Emag Medium Voltage Products

[10] D. Ito, K. Tsurunaga, E.S. Yoneda, Y. Sugiyama, Superconducting Fault Current Limiter Development, IEEE Transactions On Magnetics, Vol. 27, No. 2, March 1991

[11] Seungje Lee, Chanjoo Lee, Tae Kuk KO, Okbae Hyun, Stability Analysis of a Power System with Superconducting Fault Current Limiter Installed, IEEE Transactions On Applied Superconductivity, Vol. I I, No. I, March 2001

[12] S. Nemdili \& S. Belkhiat, Modeling and Simulation of Resistive Superconducting Fault-Current Limiters, Journal of Superconductivity And Novel Magnetism October 2012

[13] H. S. Ruiz, Z. Zhong, and T. A. Coombs, Resistive Type Superconducting Fault Current Limiters: Concepts, Materials, and Numerical Modelling, IEEE Transactions on Applied Superconductivity

[14] Feng Zheng, Changhong Deng, Lei Chen, Shichun Li, Yang Liu, and Yuxiang Liao, Transient Performance Improvement of Micro-grid by a Resistive Superconducting Fault Current Limiter, IEEE Transactions on Applied Superconductivity

[15] Arsalan Hekmati, Proposed Design for a Tunable Inductive Shield-Type SFCL, IEEE Transactions On Applied Superconductivity, Vol. 24, No. 4, August 2014

[16] Xiaoye Niu, Zhili Chen, Haizhen Wang, Zhifu Chen, Lifeng Zhang, Guojun Niu, Hui Hong \& Ying Xin, Structure and Performance Characteristics of Saturated Iron-core Superconducting Fault Current Limiter, Journal of International Council on Electrical Engineering, 10 Sep 2014.

[17] M. M. R. Ahmed, Ghanim A. Putrus, Li Ran, and Lejun Xiao, Harmonic Analysis and Improvement of a New Solid-State Fault Current Limiter, IEEE Transactions On Industry Applications, Vol. 40, No. 4, July/August 2004

[18] Teymoor Ghanbari, Ebrahim Farjah, Amir Zandnia, Development of a high-performance bridge-type fault current limiter, IET Gener. Transm. Distrib., 2014, Vol. 8, Iss. 3, pp. 486-494

[19] Teymoor Ghanbari and Ebrahim Farjah, Development of an Efficient Solid-State Fault Current Limiter for Microgrid, IEEE Transactions on Power Delivery, Vol. 27, No. 4, October 2012

[20] Seyed Behzad Naderi, Mehdi Jafari, Mehrdad Tarafdar Hagh, Parallel Resonance Type Fault Current Limiter, Accepted for publication March 29, 2012.

[21] Ji-Seong Kang \& Young-Hyun Moon, Solid-State Fault Current Limiter based on Magnetic Turn off Principle, Journal of International Council on Electrical Engineering Vol. 4, No. 2, pp.95 101, 2014

[22] Hamid Radmanesh, Hamid Fathi, Gevork B. Gharehpetian, Series Transformer-Based Solid State Fault Current Limiter, IEEE Transactions on Smart Grid

[23] EMAD. S. IBRAHIM, Electromagnetic Fault Current Limiter (EMFCL), Electric Machines and Power Systems, 25:967-975, 1997

[24] Prafulla Rajabhau Deo Tushar Pritamlal Shah, Innovative Electromagnetic Dynamic Fault Current Limiter Operating at Ambient Temperature for Smart Grids, IEEE 2010.

[25] M. Steurer, B. Drechna and IC. Friihlich, A Nitrogen Gas Cooled, Hybrid, High Temperature Superconducting Fault Current Limiter, IEEE Transactions on Applied Superconductivity, Vol 10, NO 1, March 2000

[26] Ok-Bae Hyun, Jungwook Sim, Hye-Rim Kim, Kwon-Bae Park, Seong-Woo Yim, and II-Sung Oh, Reliability Enhancement of the Fast Switch in a Hybrid Superconducting Fault Current Limiter by Using Power Electronic Switches, IEEE Transactions On Applied Superconductivity, Vol. 19, No. 3, June 2009

[27] K. Maruliya Begam1*, T. Karthikeyan2 and K. Ramani, Suppression of Fault Currents on DG Using Various Fault Current Limiters in Distribution Network, Electrical \& Electronic Systems,2014 Volume 2 , Issue 2 . 
[28] Majid Ebrahimpour, Behrooz Vahidi, and Seyed Hossein Hosseinian, A Hybrid Superconducting Fault Current Controller for DG Networks and Microgrids, IEEE Transactions On Applied Superconductivity, Vol. 23, No. 5, October 2013

[29] Lin Jiang, Jian X. Jin, and Xiao Y. Chen, Fully Controlled Hybrid Bridge Type Superconducting Fault Current Limiter, IEEE Transactions On Applied Superconductivity, Vol. 24, No. 5, October 2014

[30] M. Firouzi, G.B. Gharehpetian, B. Mozafari, Bridge-type superconducting fault current limiter effect on distance relay characteristics, Electrical Power and Energy Systems 68 (2015) 115-122 